\title{
The Breakdown and Biosynthesis of Glutamic Acid
}

\author{
BY D. S. HOARE \\ Agricultural Research Council Unit for Microbiology, \\ University of Sheffield
}

Glutamic acid is important in the carbon and nitrogen metabolism of microorganisms; it participates in the structure of the folic acid coenzymes, and is a component of the bacterial cell wall. Although a number of micro-organisms, including some of the lactic acid bacteria, require glutamate as an essential amino acid, most micro-organisms synthesize glutamate from simple carbon sources.

The biosynthesis of glutamic acid has been investigated by isotopic tracer techniques, by the use of auxotrophic mutants, and by the study of the enzymes involved in the biosynthetic pathway. The isotope technique was applied to a number of micro-organisms using differentially labelled acetate ${ }^{13} \mathrm{CH}_{3} \cdot{ }^{14} \mathrm{COOH}$ by Ehrensvärd and co-workers (Cutinelli et al. 1951 a; Ehrensvärd et al. 1951; Anderson-Kottö et al. 1954). The glutamate was not degraded completely and unequivocally. Nevertheless, the results with the aerobic micro-organisms they examined were consistent with the incorporation of acetate into glutamate via the tricarboxylic acid cycle: that is through the successive formation of citrate, aconitate, isocitrate, oxalosuccinate and $\alpha$-oxoglutarate. Wang, Christensen \& Cheldelin (1953) examined the incorporation of $\left[1-{ }^{14} \mathrm{C}\right]$-acetate and $\left[2-{ }^{14} \mathrm{C}\right]$-pyruvate into glutamate by Saccharomyces cerevisiae with results consistent with the tricarboxylic acid cycle. This technique has also been applied to glutamate biosynthesis in higher plants and animals (Bilinski \& McConnell, 1957; Koeppe \& Hill, 1955; Black \& Kleiber, 1957; Black et al. 1957).

Ehrensvärd and co-workers extended their studies to the anaerobic photosynthetic bacterium Rhodospirillum rubrum using ${ }^{13} \mathrm{CH}_{3} \cdot{ }^{14} \mathrm{COOH}$ and $\mathrm{NaH}^{14} \mathrm{CO}_{3}$ (Cutinelli et al. 1951 b). Again the isolated glutamate was not completely and unequivocally degraded although the results were different from those found with the aerobic bacteria. Alanine was also isolated and degraded and was found to be specifically labelled in a manner different from that found in aerobes (Table 1). Assuming the alanine to be derived directly from pyruvate, the glutamate degradation data were consistent with its formation via the following series of reactions including part of the tricarboxylic acid cycle:

$$
\begin{gathered}
\text { pyruvate }+\mathrm{CO}_{2} \rightarrow \text { oxalacetate } \\
\text { oxalacetate }+ \text { acetate } \rightarrow \text { citrate } \rightarrow \text { isocitrate } \rightarrow \\
\text { oxalosuccinate } \rightarrow \text {-oxoglutarate } \rightarrow \text { glutamate. }
\end{gathered}
$$

The final step in the above reaction sequence could be carried out by glutamic dehydrogenase or transaminases. Hug \& Werkman (1957) showed that $R$. rubrum possessed transaminases capable of catalysing the final step in the reaction sequence.

The isotope technique was extensively used in studies of amino acid biosynthesis in Escherichia coli by Roberts et al. (1955), and their successful application of the 'isotopic competition' method showed that glutamic acid, formed via the tri- 
carboxylic acid cycle, was a precursor of other amino acids including proline and arginine; results which were consistent with earlier studies on the biosynthesis of these amino acids in micro-organisms (notably work with auxotrophic mutants of Neurospora crassa). Similarly, aspartic acid was shown to be a precursor of threonine, isoleucine, methionine and lysine. It was thus clear that the tricarboxylic acid cycle in $\boldsymbol{E}$. coli was an important source of cell constituents, especially amino acids. These findings supported the earlier conclusions of Krebs, Gurin \& Eggleston (1952) as a result of their studies on acetate metabolism in yeast. However, it yet remained to be established that the tricarboxylic acid cycle was the only significant source of glutamate in micro-organisms. This was demonstrated very clearly by Gilvarg \& Davis (1956) with auxotrophic mutants of $\boldsymbol{E}$. coli and Aerobacter aerogenes. These mutants were blocked at the citrate condensing enzyme and had an absolute requirement for glutamate, and were unable to oxidize acetate.

A number of bacteria and fungi accumulate $\alpha$-oxoglutarate, particularly when grown with nitrogen as the growth-limiting constituent (Walker, Hall \& Hopton, 1951; Hockenhull, Wilkin \& Winder, 1951; Dagley, Fewster \& Happold, 1952). These results suggest that $\alpha$-oxoglutarate is the precursor of glutamate in these micro-organisms. $\alpha$-Oxoglutarate accumulation has been found with species of Pseudomonas (Lockwood \& Stodola, 1946; Kogut \& Podoski, 1953) for which there is independent evidence for the operation of the tricarboxylic acid cycle which could give rise to $\alpha$-oxoglutarate (Clarke \& Meadow, 1959).

The tricarboxylic acid cycle may not be involved in $\alpha$-oxoglutarate synthesis, and hence glutamate formation, in all aerobes : $\alpha$-oxoglutarate can be formed fromL-arabinose by a route independent of the tricarboxylic acid cycle in Pseudomonas saccharophila (Weimberg \& Doudoroff, 1955). Some species of acetic acid bacteria, including Acetobacter suboxydans and A. melanogenus, can synthesize glutamic acid although they appear to be deficient in key enzymes of the tricarboxylic acid cycle (Rao, 1957). Glutamate biosynthesis in $A$. suboxydans has recently been investigated by Sekizawa et al. (1962) and a novel mechanism for its biosynthesis has been proposed. Kinetic studies with the green alga Chlorella pyrenoidosa (Bassham \& Kirk, 1960; Smith, Bassham \& Kirk, 1961) suggest that glutamate may not be synthesized via citrate. It was found that the rate of formation of citrate in an actively photosynthesizing cell suspension was considerably less than the rate of formation of glutamate.

There is now little doubt that novel mechanisms of amino acid synthesis operate in some strict anaerobes. This was first clearly demonstrated for the biosynthesis of alanine and glutamic acid in Clostridium kluyveri (Tomlinson, 1954a, b). Recent studies on rumen anaerobes, e.g. Ruminococcus flavefaciens, confirm novel pathways for the biosynthesis of valine and leucine (Allison, Bryant \& Doetsch, 1962). The glutamate formed in $C$. kluyveri from $\left[1^{-14} \mathrm{C}\right]$-acetate and from $\mathrm{NaH}^{14} \mathrm{CO}_{3}$ was degraded unequivocally and the isotope distribution was not consistent with any known metabolic reaction sequence (Table 1). As yet no enzyme studies have been carried out to elucidate the mechanism of glutamate biosynthesis in C. kluyveri. A common feature of the amino acids synthesized by the above anaerobes and by R. rubrum is the specific incorporation of bicarbonate into a carboxyl group.

Recent studies on the photoassimilation of acetate by Rhodospirillum rubrum stimulated a re-investigation of the isotope incorporation of acetate into glutamate 
in this organism ((Hoare, 1962a,b). In short exposure experiments in which washed cell suspensions of $\boldsymbol{R}$. rubrum were exposed in the light to $\left[1^{14} \mathrm{C}\right]-$ or $\left[2-{ }^{14} \mathrm{C}\right]$-acetate in the presence of bicarbonate, one of the earliest detectable products of photoassimilation was found to be glutamic acid. This appeared to be formed before one could detect intermediates of the tricarboxylic acid cycle. The failure to detect the latter at the shortest exposures might have been due to their small pool size, although this seemed unlikely since they were readily detected when $\mathrm{Na}_{2}{ }^{14} \mathrm{CO}_{3}$ was assimilated in the light in the presence of acetate. The glutamate formed under the above conditions was degraded and the isotope distribution differed from that found in Clostridium kluyveri and from that found in aerobic organisms in which glutamate is formed via the tricarboxylic acid cycle (Table 1).

Table 1. Isotope incorporation into alanine and glutamic acid

$\mathrm{b}=$ carbon atoms derived from bicarbonate. $\mathrm{c}=$ carbon atoms derived from carboxyl (C-1) of acetate. $m=$ carbon atoms derived from methyl (C-2) of acetate.

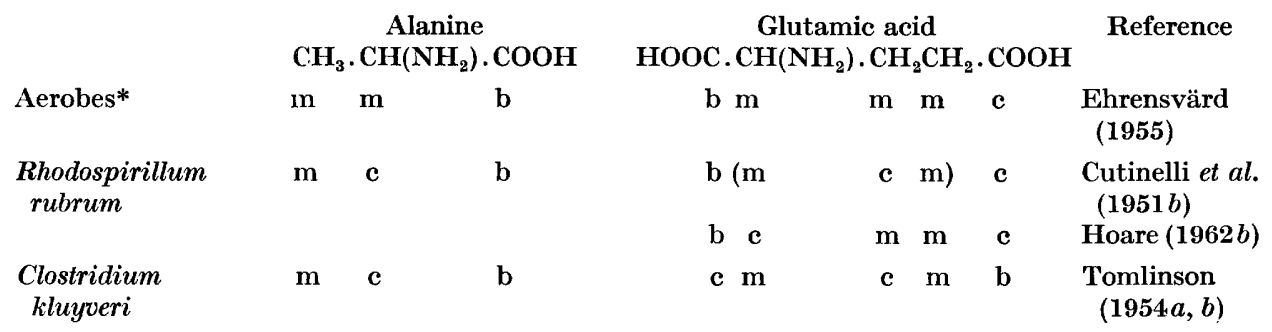

* Assuming the biosynthesis proceeds via the tricarboxylic acid cycle.

Studies of Cutinelli et al. $(\mathbf{1 9 5 1} b)$ did not establish an unequivocal distribution of carbon atoms 2 , 3 and 4 of glutamic acid.

In aerobic bacteria it is generally assumed that the breakdown of glutamic acid proceeds via $\alpha$-oxoglutarate and the tricarboxylic acid cycle. The wide distribution of transaminases and of glutamic dehydrogenase is in accord with this view. A number of anaerobic bacteria degrade glutamic acid to carbon dioxide and volatile fatty acids including mainly acetate and butyrate. Conversion of glutamate to acetate via the tricarboxylic acid cycle should result in the formation of three moles of $\mathrm{CO}_{2}$ per mole of glutamate. Several strict anaerobes, including Clostridium tetani (Clifton, 1942), C. saccharobutyricum (Cohen, Nisman \& Cohen-Bazire, 1948), C. tetanomorphum (Woods \& Clifton, 1937; Barker, 1937), Micrococcus aerogenes (Whiteley, 1957) and Fusobacterium nucleatum (Jackins \& Barker, 1951), ferment glutamate with the formation of only 1 mole of $\mathrm{CO}_{2}$. The fermentation of glutamate has been studied very thoroughly with $C$. tetanomorphum. Isotopic tracer studies showed that the $\mathrm{CO}_{2}$ was derived exclusively from C-5 of glutamic acid, acetate mainly from C-1 and C-2 and butyrate from C-3 and C-4 (Wachsman \& Barker, 1955; Wachsman, 1956). The enzyme steps involved in the degradation of glutamate by $C$. tetanomorphum have now been identified and studied in some detail. The initial enzyme step catalysing the isomerization of glutamic acid to $\beta$-methylaspartic acid was found to involve a coenzyme derivative of vitamin $\mathbf{B}_{12}$ (Barker, Weissbach \& Smyth, 1958). It is not yet known whether glutamate fermentation by C. tetani, C. saccharobutyricum and $F$. nucleatum proceeds by a similar mechanism to that in C. tetanomorphum. 
Clearly the anaerobic bacteria merit a more extensive investigation with the possibilities of finding new pathways in the biosynthesis and degradation of amino acids. It is by no means established that the tricarboxylic acid cycle functions in strict anaerobes and, since such organisms may not depend upon it for a source of reducing power, they may prove to have evolved some alternative mechanism for providing intermediates for amino acid biosynthesis. A number of strict anaerobes, in addition to Clostridium kluyveri (which is the only one to be examined so far), use two carbon compounds as sole carbon sources and an examination of glutamate biosynthesis in these organisms would be of particular interest. Some of the methane bacteria and several organisms fermenting nitrogenous compounds (Streptococcus allantoicus, Peptococcus glycinophilus, Clostridium cylindrosporum and Clostridium acidi-urici) fall in this category.

\section{REFERENCES}

Allison, M. J., Bryant, M. P. \& Doetsch, R. W. (1962). Studies on the metabolic function of branched chain volatile fatty acids, growth factors for ruminococcus. I. Incorporation of isovalerate into leucine. J. Bact. 83, 523 .

Anderson-Kottö, I., Ehrensvärd, G., Reio, L., Saluste, E. \& StJernholm, R. (1954). Amino-acid formation and utilization in Neurospora. J. biol. Chem. 210, 445.

BARKER, H. A. (1937). On the fermentation of glutamic acid. Enzymologia, $2,175$.

Barker, H. A., Weissbach, H. \& Smyth, R. D. (1958). A coenzyme containing pseudovitamin $\mathrm{B}_{12}$. Proc. nat. Acad. Sci., Wash. 44, 1093.

Bassham, J. A. \& Kirk, M. (1960). Dynamics of the photosynthesis of carbon compounds. I. Carboxylation reactions. Biochim. biophys. Acta, 43, 447.

Bilinski, E. \& McConnell, W. B. (1957). Studies on wheat plants using $\mathrm{C}^{14}$ compounds. IV. Distribution of $\mathrm{C}^{14}$ in glutamic acid, aspartic acid and threonine arising from acetate-1-C ${ }^{14}$ and -2-C ${ }^{14}$. Canad J. Biochem. Physiol. 35, 365.

BlACK, A. L. \& KLeIBER, M. (1957). The tricarboxylic acid cycle as a pathway for transfer of carbon from acetate to amino acids in the intact cow. Biochim. biophys. Acta, 23, 59.

Black, A. L., Kleiber, M., Smith, A. H. \& Stewart, D. N. (1957). Acetate as a precursor of amino acids of easein in the intact dairy cow. Biochim. biophys. Acta, 23, 54.

Clarke, P. \& Meadow, P. (1959). Evidence for the occurrence of permeases for tricarboxylic acid cycle intermediates in Pseudomonas aeruginosa. J. gen. Microbiol. 20, 144.

Clifton, C. E. (1942). The utilization of amino acids and related compounds by Clostridium tetani. J. Bact. 44, 179.

Cohen, G. N., Nisman, B. \& Cohen-Bazire, G. (1948). Sort des amino-acides dégradés par Cl. saccharobutyricum et Cl. sporogenes. Bull. Soc. Chim. biol., Paris, 30, 109.

Cutinelli, C., Ehrensvärd, G., Reio, L., Saluste, E. \& Stjernholm, R. (1951 $a$ ). Acetic acid metabolism in Escherichia coli. I. General features, and the metabolic connection between acetate and glutamic acid, aspartic acid, glycine, alanine, valine, serine and threonine. Acta chem. scand. 5, 353.

Cutinelit, C., Ehrensvärd, G., Reio, L., Saluste, E. \& Stjernholm, R. (1951 b). Acetic acid metabolism in Rhodospirillum rubrum under anaerobic conditions. II. Arkiv. Kemi, 3, 315.

Dagley, S., Fewster, M. E. \& Happold, F. C. (1952). The bacterial oxidation of phenylacetic acid. J. Bact. 63, 327.

Ehrensvärd, G. (1955). Metabolism of amino acids and proteins. Annu. Rev. Biochem. 24, 275.

Ehrensvärd, G., Reio, L., Saluste, E. \& Stjernholm, R. (1951). Acetic acid metabolism in Torulopsis utilis. III. Metabolic connection between acetic acid and various amino acids. J. biol. Chem. 189, 93.

Gilvarg, C. \& Davis, B. D. (1956). The role of the tricarboxylic acid cycle in acetate oxidation in Escherichia coli. J. biol. Chem. 222, 307. 
Hoare, D. S. $(1962 a)$. The photometabolism of [1-14 C $]$ acetate and [2-14 C]-acetate by washed cell suspensions of Rhodospirillum rubrum. Biochim. biophys. Acta, 59, 723.

HoARE, D. S. $(1962 b)$. The photoassimilation of acetate to glutamate in washed cell suspensions of Rhodospirillum rubrum. Biochem. J. 84, $94 P$.

Hockenhull, D. J. D., Wilkin, G. D. \& Winder, F. G. (1951). Production of $\alpha$-ketoglutarate by Penicillium chrysogenum. Nature, Lond., 168, 1043.

Hug, D. H. \& Werkman, C. H. (1957). Transamination in Rhodospirillum rubrum. Arch. Biochem. 72, 369.

JaCkins, H. C. \& Barker, H. A. (1951). Fermentative processes of the fusiform bacteria. J. Bact. 61, 101.

Koeppe, R. E. \& Hill, R. J. (1955). The incorporation of carboxyl and bicarbonate carbon into glutamic acid by the rat. J. biol. Chem. 216, 813.

Kogut, M. \& Podoski, E. P. (1953). Oxidative pathways in a fluorescent pseudomonas. Biochem. J. 55, 800.

Krebs, H. A., Gurin, S. \& Eggleston, L. V. (1952). 'The pathway of oxidation of acetate in baker's yeast. Biochem. J. 51, 614 .

Lockwood, L. B. \& Stodola, F. H. (1946). Preliminary studies on the production of $\alpha$-ketoglutaric acid by Pseudomonas fluorescens. J. biol. Chem. 164, 81.

RAo, M. R. R. (1957). Acetic acid bacteria. Annu. Rev. Microbiol. 11, 317.

Roberts, R. B., Cowie, D. B., Abelson, P. H., Bolton, E. T. \& Britten, R. J. (1955). Studies of biosynthesis in Escherichia coli. Publ. Carneg. Instn, no. 607.

Sekizawa, Y., Maragoudakis, M. E., Kerwar, S. S., Flikke, M., Baich, A., King, T. E. \& Cheldelin, V. H. (1962). Glutamic acid biosynthesis in an organism lacking a Krebs tricarboxylic acid cycle. Biochem. Biophys. Res. Comm. 9, 361.

Smith, D. C., Bassham, J. A. \& Kirk, M. (1961). Dynamics of the photosynthesis of carbon compounds. II. Amino acid synthesis. Biochim. biophys, Acta, 48, 299.

Tombinson, N. (1954a). Carbon dioxide and acetate utilization by Clostridium kluyveri. II. Synthesis of amino acids. J. biol. Chem. 209, 585 .

Tomlinson, N. (1954b). Carbon dioxide and acetate utilization by Clostridium kluyveri. III. A new path of glutamic acid synthesis. J. biol. Chem. 209, 605.

WACHSMAN, J. T. (1956). The role of $\alpha$-ketoglutarate and mesaconate in glutamate fermentation by Clostridium tetanomorphum. J. biol. Chem. 223, 19.

Wachsman, J. T. \& Barker, H. A. (1955). Tracer experiments on glutamate fermentation by Clostridium tetanomorphum. J. biol. Chem. 217, 695.

Walker, T. K., Hall, A. N. \& Hopton, J. W. (1951). Chromatographic detection of pyruvic, dimethylpyruvic and $\alpha$-ketoglutaric acids in cultures of Aspergillus niger on various substrates. Nature, Lond. 168, 1042.

Wang, C. H., Christensen, B. E. \& Cheldelin, V. H. (1953). Conversion of acetate and pyruvate to glutamic acid in yeast. J. biol. Chem. 201, 683.

Weimberg, R. \& Doudoroff, M. (1955). The oxidation of L-arabinose by Pseudomonas saccharophila. J. biol. Chem. 217, 607.

Whiteley, H. R. (1957). Fermentation of amino acids by Micrococcus aerogenes. J. Bact. 74, 324.

Woods, D. D. \& Clifton, C. E. (1937). Hydrogen production and amino acids utilization by Clostridium tetanomorphum. Biochem. J. 32, 1774. 